\title{
Percepção das pessoas idosas frente o respeito e a inclusão social no município de Balneário Camboriú
}

The elder face perception respect and social inclusion in the city of Balneário Camboriú

Daiana Caroline Prestes Feil*

Flávia de Souza Fernandes**

Alexandre Vanzuíta***

Aline Daiane Schlindwein****

\section{Resumo}

O presente estudo foi realizado por solicitação da prefeitura de Balneário Camboriú (BC) para embasar políticas públicas para à população idosa, e como requisito para o município participar da Rede de Cidades e Comunidades Amigáveis à Pessoa Idosa da OMS e a Estratégia Brasil Amigo da Pessoa Idosa do governo federal. $\mathrm{O}$ objetivo foi analisar a percepção da pessoa idosa de Balneário Camboriú/SC frente ao respeito e a inclusão social. Trata-se de uma pesquisa de natureza quali-quantitativa de perspectiva analítico-descritiva com duzentas (200) pessoas idosas. Os instrumentos de coleta de dados foram a aplicação do questionário e um grupo focal, em meados do ano de 2018. Os resultados demonstraram que $35 \%$ não participam de atividades de convivência e fortalecimento de vínculos; $98 \%$ não participam de espaço de discussão coletiva de direitos; $57 \%$ estão incluídos no Cadúnico e $62,5 \%$ desconhece os serviços oferecidos nos Centros de Referência de Assistência Social - CRAS. Identificou-se a necessidade de ampliar benefícios, serviços, programas e projetos para outros territórios de $\mathrm{BC}$, qualificar o acesso à informação para a população idosa e incentivar a participação nas instâncias de controle social. Entretanto, observou-se que outros municípios do Brasil, e de outros países apresentam expressões da questão social semelhantes à BC.

Palavras-chave: Políticas públicas. Pessoas idosas. Garantia de direitos. Respeito e inclusão social.

\section{Abstract}

This study was carried out at the request of the city of Balneário Camboriú (BC) to support public policies for the elderly population, and as a requirement for the municipality to participate in the WHO Network of Cities and Communities Friendly to the Elderly and the Brasil Amigo da Pessoa Strategy Elderly of the federal government. The objective was to analyze the perception of the elderly in Balneário Camboriú I SC regarding respect and social inclusion. It is a qualitative and quantitative research from an analytical-descriptive perspective with two hundred (200) elderly people. The data collection instruments were the application of the questionnaire and a focus group, in mid-2018

The results showed that $35 \%$ do not participate in activities of coexistence and strengthening of bonds; $98 \%$ do not participate in a space for collective discussion of rights; $57 \%$ are included in Cadúnico and $62.5 \%$ are unaware of the services offered at the Social Assistance Reference Centers - CRAS. The need to expand benefits, services, programs and projects to other $B C$ territories was identified, to qualify access to information for the elderly population and to encourage participation in social control bodies. However, it was observed that other municipalities in Brazil and other countries present expressions of the social issue similar to $B C$.

Keywords: Public policies. Old people. Guarantee of rights. Respect and social inclusion.

\footnotetext{
* Discente do Mestrado em Saúde e Gestão do Trabalho (UNIVALI). Assistente Social na Prefeitura Municipal de Balneário Camboriú - SC.

** Doutoranda em Ciências da Saúde (UNISUL). Professora Permanente do Instituto Federal Catarinense Campus Camboriú

*** Doutor em Educação (UNIVALI) e Pós Doutor em Educação (UNIVALI). Coordenador Adjunto do Programa de Pós-Graduação Stricto Sensu em Educação - Instituto Federal Catarinense e Professor Permanente deste Programa. Coordenador Institucional PIBID - IFCatarinense.

**** Mestre e Doutora em Biotecnologia e Biociências (UFSC). Diretoria de Educação Permanente. É Servidora da Secretaria de Estado da Saúde - Santa Catarina.
} 


\section{Introdução}

O censo realizado em 2010 pelo Instituto Brasileiro de Geografia e Estatística (IBGE) identificou que havia 20,6 milhões de pessoas com 60 anos ou mais de idade no Brasil. Naquele ano o IBGE também projetou o incremento médio de mais de 1 milhão de pessoas idosas a cada ano (BRASIL, 2018b).

Em 2017 a Pesquisa Nacional por Amostra de Domicílios (PNAD Contínua) indicou que, entre 2012 e 2016, o percentual de pessoas idosas no país passou de $12,8 \%$ para $14,4 \%$. 0 IBGE estima que em 2050 existam mais idosos do que crianças no Brasil (BRASIL, 2018b).

Em 2010 o estado de Santa Catarina (SC) contava com uma população de 6.248 .436 habitantes, destes, 10,5\% são pessoas idosas. O município de Balneário Camboriú (BC) possui atualmente 108.089 habitantes, destes, 12.753 são pessoas acima dos 60 anos. Esse dado representava naquela época mais de $10 \%$ da população da cidade (SEBRAE, 2013).

Um caso peculiar do município e que se destaca na realidade nacional é a criação da Secretaria da Pessoa Idosa (SPI). Esta Secretaria foi criada por meio da lei municipal $n^{\circ} 3461$, de 15 de junho de 2012 (BALNEÁRIO CAMBORIÚ, 2012) e por este motivo, BC está à frente de outros municípios, pois possui legislação direcionada a pessoa idosa, sendo elas: Política Municipal da Pessoa Idosa (BALNEÁRIO CAMBORIÚ, 2015); Fundação Municipal do Idoso (BALNEÁRIO CAMBORIÚ, 2017) e o Fundo Municipal do Idoso de Balneário Camboriú (BALNEÁRIO CAMBORIÚ, 2018).

Diante das projeções de aumento e, em consequência, a necessidade de políticas públicas que garantam qualidade de vida à população idosa, a Organização Mundial de Saúde (OMS), por meio da Organização Pan Americana de Saúde (OPAS) oferece apoio técnico aos municípios que compõem a Rede de Cidades e Comunidades Amigáveis à Pessoa Idosa. A OMS concede o Certificado de Cidade Amiga da Pessoa Idosa aos municípios que assumam o compromisso de planejar ações que beneficiam os envelhecentes, por meio de políticas, serviços, ambientes e estruturas que permitem melhorar a saúde e a qualidade de vida das pessoas idosas (BRASIL, 2018b).

Outra iniciativa que se destaca é a Estratégia Brasil Amigo da Pessoa Idosa (EBAPI), proposta do governo federal, a qual incentiva estados e municípios a efetivarem por meio de políticas públicas o Estatuto do Idoso. A EBAPI tem o objetivo de "garantir os direitos das pessoas idosas em todos os setores, como meio para atender as necessidades da população idosa” (BRASIL, 2018b, p. 14). "Para incentivar a participação dos entes federados, a EBAPI 
concede cinco selos de reconhecimento aos municípios, sendo estes, os selos de adesão, plano, bronze, prata e ouro" (BRASIL, 2018b, p. 17). Um dos requisitos da EBAPI é a realização do Diagnóstico Municipal da Pessoa Idosa e o Plano Municipal da Estratégia, contendo ações necessárias para o desenvolvimento do envelhecimento ativo, saudável, sustentável e cidadão da pessoa idosa no município (BRASIL, 2018d).

O município de $\mathrm{BC}$ em SC, reconhecido nacionalmente por ter expressiva população idosa, aderiu às duas iniciativas supracitadas em 2017 e 2018, respectivamente. Para tanto, ambas exigem a realização do Diagnóstico Municipal da Pessoa Idosa, que compreende a descrição e análise de diferentes dimensões, entre estes o de "respeito e inclusão social", o qual foi o objetivo do presente estudo, assim como, a análise e a percepção das pessoas quanto as políticas públicas existentes e a implementação de novas políticas públicas para melhoria neste setor.

\section{Métodos}

A presente pesquisa seguiu o protocolo de amostragem, coleta de dados e análise do Documento Técnico II da Estratégia Brasil Amigo da Pessoa Idosa (BRASIL, 2018c). Trata-se de uma abordagem quali-quantitativa de perspectiva analítico-descritiva (BOGDAN, 2013).

Os dados produzidos no presente estudo, no primeiro momento, foram por meio de questionário com perguntas abertas e fechadas com duzentas (200) pessoas idosas residentes no município de BC.

Como critérios de inclusão foi delimitado os seguintes aspectos: pessoas entre 60 a 90 anos, de ambos os sexos, em boas condições de saúde, legalmente capazes de participar dos dois momentos da pesquisa, ou seja, responder o questionário e participar do grupo focal. Como critérios de exclusão elencados foram: incapacidade cognitiva e/ou de transtorno de ansiedade de responder às perguntas do questionário e do grupo focal.

Todos os participantes desta pesquisa assinaram o Termo de Consentimento Livre e Esclarecido (TCLE) e autorização de imagem e voz, recebendo as orientações referentes à pesquisa e ficando livres para negar-se a participar do estudo em qualquer momento.

O questionário aplicado estava dividido em oito dimensões: ambiente físico; moradia; transporte; participação; oportunidade de aprendizagem; comunicação e informação; apoio, 
cuidado e saúde; turismo e lazer; e; respeito e inclusão social. Este último foco deste trabalho, analisa a percepção dos participantes da pesquisa sobre as políticas públicas nesta área.

Antes da aplicação do questionário foi realizada capacitação dos entrevistadores no Instituto Federal de Educação, Ciência e Tecnologia Catarinense (IFC Campus Camboriú) com vinte (20) pessoas idosas que auxiliaram no processo de investigação. A aplicação do questionário ocorreu em diferentes pontos estratégicos do território de $\mathrm{BC}$, em seis (6) encontros.

Em seguida, o grupo focal foi realizado na SPI com a presença de seis (6) pessoas idosas que foram sorteadas entre todos os participantes. A duração do grupo focal foi de $2 \mathrm{~h}$ e $30 \mathrm{~min}$. O grupo focal (GATTI, 2012) trata-se de uma abordagem empírica qualitativa.

Os dados do questionário foram digitados em planilha do Microsoft Windows Excel e posteriormente exportados para o software IBM SPSS Statistics versão 18.0 e software Graph Pad Prism (San Diego, EUA), para posterior análise.

A invenção dos códigos de nomes para os sujeitos da pesquisa foi denominado como espécies de "flores", após a transcrição do grupo focal, para manter o sigilo dos(as) participantes para os fins das análises do material produzido. O Quadro 1 apresenta os sujeitos da pesquisa participantes da SPI de BC. Suas naturalidades e gênero serão apresentadas tendo como finalidade compreender suas subjetividades.

Quadro 1 - Caracterização dos participantes do grupo focal

\begin{tabular}{|c|c|c|}
\hline Nome Fictício & Naturalidade & Gênero \\
\hline Cravo & Porto Seguro/BA & Masculino \\
\hline Antúrio & Trindade/RS & Masculino \\
\hline Azaleia & Vacaria/RS & Feminino \\
\hline Rosa & Vacaria/RS & Feminino \\
\hline Orquídea & Rio do Sul/SC & Feminino \\
\hline Hortência & Pinhalão/PR & Feminino \\
\hline
\end{tabular}

Fonte: Dados obtidos pelos(as) pesquisadores(as) por meio do grupo focal.

As variáveis qualitativas foram apresentadas na forma de frequência simples e relativa. Além disso, foi realizada a análise interpretativa, que buscou-se aprofundar a discussão por meio da triangulação dos dados utilizando a fundamentação teórica, os dados da empiria e a crítica analítica e reflexiva na presente investigação.

Essa investigação foi submetida e aprovada pelo Comitê de Ética em Pesquisa com 
Seres Humanos (CEPSH) do Instituto Federal de Educação, Ciência e Tecnologia Catarinense (IFCatarinense) com o número do parecer 2.770 .213 e registro CAAE 90413818.0.0000.8049.

\title{
Resultados e Discussão
}

A discussão acerca do Respeito e Inclusão Social da pessoa idosa perpassa pela reflexão sobre a garantia de direitos (FERREIRA; TEIXEIRA, 2014). Os instrumentos legais como a Constituição Federal (CF), a Política Nacional do Idoso e o Estatuto do Idoso, isoladamente, não garantem o envelhecimento ativo, saudável, sustentável e cidadão. É preciso o engajamento de todos os atores que constituem a sociedade para efetivar estes direitos.

No caso do município estudado, este possui iniciativas em prol da população idosa, e oferece diferentes serviços, projetos e programas que visam promover respeito e inclusão social. Em paradoxo, os dados que serão demonstrados abaixo demonstram que estas garantias legais ainda não atendem todas as necessidades da população idosa referente ao que a OMS define como respeito e inclusão social.

\begin{abstract}
Respeito e a inclusão social dos idosos dependem de outros fatores, além das mudanças sociais: cultura, gênero, condição de saúde e status econômico têm um papel importante na inserção social dos idosos. O grau de participação dos idosos na vida social, cívica e econômica da cidade está, também, intimamente relacionado à experiência deles de inclusão (OMS, 2008, p. 41).
\end{abstract}

Nesta pesquisa, quando os participantes foram questionados sobre ter conhecimento referente a estes serviços, programas e projetos executados em BC, constatou-se que o Programa Pense Leve, que realiza ações de promoção de saúde, é o mais frequentado (Tabela 01). Embora muitas pessoas idosas relataram conhecer os serviços, programas e projetos oferecidos, $35 \%$ deles não participam de nenhum deles.

Tabela 1 - Percepção das pessoas idosas entrevistadas quanto aos Programas e atividades oferecidas pelo município de Balneário Camboriú ( $n=200)$. Balneário Camboriú, 2018

\begin{tabular}{c|c|c}
\hline Programa e atividade & Número de respondentes & Porcentagem (\%) \\
\hline Nenhum & 70 & 35,0 \\
\hline Pense Leve & 29 & 14,5 \\
\hline Alongamento & 25 & 12,5 \\
\hline Dança & 16 & 8,0 \\
\hline Academia da mente & 12 & 6,0 \\
\hline Idiomas & 10 & 5,0 \\
\hline Outros & 09 & 4,5 \\
\hline Bingo & 06 & 3,0
\end{tabular}




\begin{tabular}{c|c|c}
\hline Baile & 06 & 3,0 \\
\hline Coral & 06 & 3,0 \\
\hline Canto & 04 & 2,0 \\
\hline Yoga & 03 & 1,5 \\
\hline Pilates & 02 & 1,0 \\
\hline Reiki & 02 & 1,0 \\
\hline
\end{tabular}

Fonte: Dados obtidos pelos(as) pesquisadores(as) por meio do questionário.

Em estudo semelhante a este, realizado em Belo Horizonte, Minas Gerais, foi identificado ser imprescindível que a "população idosa seja estimulada pela família, pela comunidade e pelo Estado, sendo que este deve oferecer incentivos através da organização e execução de atividades" (PORTO; REZENDE, 2018, p. 64).

Em Belo Horizonte, os entrevistados daquela pesquisa, assim como os de BC, relataram que estão satisfeitos com as atividades ofertadas naquele município, porém, percebem a necessidade de ampliar a variedade de serviços, programas e projetos, principalmente culturais. Naquela cidade, eles apontaram que "os grupos se reúnem principalmente em espaços cedidos, o que muitas vezes dificulta a quantidade de encontros" (PORTO; REZENDE, 2018, p. 64). É fundamental que existam equipamentos públicos com infraestrutura adequada para a execução de ações em prol da população idosa, bem como, este público tenha autonomia para ocupar espaços, gerindo-os de acordo com suas necessidades.

Esta participação está prevista no Estatuto do Idoso, Lei n 10.741/2003, em seu art. $20^{\circ}$ que garante que "o idoso tem direito a educação, cultura, esporte, lazer, diversões, espetáculos, produtos e serviços que respeitem sua peculiar condição de idade" (BRASIL, 2003, p. 3).

A Tabela 2 apresenta as atividades ou oficinas que as pessoas idosas gostariam que BC ofertasse. Como é possível observar, várias atividades são sugeridas, porém, 57,5\% não desejam realizar nenhuma ou estão satisfeitas com o que o município já oferece. Ressalta-se que algumas oficinas sugeridas acontecem em alguns locais do município, porém não abrangem todo o território. Sendo assim, é necessário instrumentalizar a população idosa e atores sociais para discutir com os gestores sobre a ampliação das atividades ofertadas.

Tabela 2 - Atividades/oficinas sugeridas pelos entrevistados a serem oferecidas pela gestão municipal à população idosa de Balneário Camboriú $(n=200)$. Balneário Camboriú, 2018

\begin{tabular}{c|c|c}
\hline Atividade sugerida & Quantidades de respostas & Porcentagem (\%) \\
\hline Nenhuma & 115 & 57,5 \\
\hline Hidroginástica & 22 & 11,0
\end{tabular}




\begin{tabular}{c|l|l}
\hline Natação & 10 & 5,0 \\
\hline Outros & 08 & 4,0 \\
\hline Profissionalizante & 07 & 3,5 \\
\hline Costura & 06 & 3,0 \\
\hline Crochê & 06 & 3,0 \\
\hline Mais atividades de dança & 05 & 2,5 \\
\hline Culinária & 05 & 2,5 \\
\hline Ginástica e alongamento & 05 & 2,5 \\
\hline Artesanato & 05 & 2,5 \\
\hline Idiomas & 04 & 2,0 \\
\hline Pintura & 02 & 1,0 \\
\hline
\end{tabular}

Fonte: Dados obtidos pelos(as) pesquisadores(as) por meio do questionário.

A divulgação das atividades ofertadas pelo município é realizada por meio de rádio, televisão e internet, no entanto, observou-se que é necessário investir em outros meios para divulgar os serviços oferecidos.

\begin{abstract}
Em todos os lugares, valorizam-se as informações que chegam as pessoas idosas em sua vida diária e em suas atividades, seja boca-a-boca, por telefone e por meio de panfletos distribuídos em lugares-chave como centros comunitários e quadros de avisos, repartições públicas, bibliotecas, lojas, consultórios médicos e clínicas de saúde (OMS, 2008, p. 53).
\end{abstract}

Nota-se que a divulgação das informações deve ser perene, para que as pessoas idosas usufruam daquilo que é ofertado a elas.

Essa afirmação vai ao encontro das projeções de aumento do envelhecimento populacional no Brasil, que são projetadas pelo Censo Demográfico (IBGE, 2012) e em sequência pela Pesquisa Nacional por Amostra de Domicílio (IBGE, 2018). Nestas pesquisas é possível identificar a necessidade de implementar políticas públicas que garantam qualidade de vida para os senescentes, numa perspectiva de promoção de direitos não somente em BC, mas em todo o país. "É necessário incentivar o controle social, a participação e a representatividade de todos os segmentos da população na construção e implementação destas políticas" (FERREIRA; TEIXEIRA, 2014).

No presente estudo foi identificado que a maioria dos entrevistados (98\%) não frequentam os espaços públicos de controle social, como por exemplo o Conselho de Saúde, Educação e Segurança Pública (Tabela 3) o que demonstra a falta de representatividade deste segmento. 
Tabela 3 - Participação das pessoas idosas entrevistadas em espaços de controle social em Balneário Camboriú ( $n=200)$. Balneário Camboriú, 2018

\begin{tabular}{c|c|c}
\hline Espaços de controle social & Número de respondentes & Porcentagem (\%) \\
\hline Não participa & 196 & 98,0 \\
\hline $\begin{array}{c}\text { Conselho Municipal do } \\
\text { Idosos }\end{array}$ & 02 & 1,0 \\
\hline $\begin{array}{c}\text { Conselho Municipal da } \\
\text { Mulher }\end{array}$ & 01 & 0,5 \\
\hline Associação de bairros & 01 & 0,5 \\
\hline
\end{tabular}

Fonte: Dados obtidos pelos(as) pesquisadores(as) por meio do questionário.

Durante o grupo focal foi justificada a falta de participação nas instâncias consultivas e deliberativas, por exemplo na fala de Orquídia: “Eu também não participo porque não tenho tempo. Me falta tempo para isso". Azaleia relata: "Não! Não tenho tempo, você tem que ralar tanto que não tem tempo para isso". Hortência complementa: "Eu também"! Dentre os entrevistados, Cravo expressa ter interesse em participar: "[...] eu participei algumas vezes do conselho do bairro, fui convidado e fui voluntariamente. Pretendo participar mais vezes, para conhecer mais as coisas e as pessoas. Se puderem me levar eu participo, mas do contrário, não sairia de casa". De acordo com a OMS (2008, p. 37), "por vezes os horários das atividades são rígidos e os idosos precisam optar entre suas necessidades pessoais, como o cochilo habitual da tarde ou a participação em uma atividade". Dessa forma é preciso observar se as barreiras para a participação social das pessoas idosas nesses espaços estão dificultando o seu acesso.

No estudo realizado em Belo Horizonte os entrevistados reconheceram a importância da participação, e que poderiam contribuir mais através dela. Apesar de considerarem que possuem voz ativa, entendem que não são ouvidos de maneira adequada, e o retorno do poder público é insuficiente para atender suas demandas. Sugerem o aumento de atividades socioeducativas de forma clara e em linguagem acessível para socialização de conhecimentos sobre seus direitos, e em consequência ampliação da participação social (PORTO; REZENDE, 2018).

De acordo com Paiva et al. (2019) em Coimbra, Portugal, também foi realizado estudo similar a este, denominado "Percepção da cidade e qualidade de vida de uma amostra de pessoas idosas". Neste, a dimensão participação foi dividida em "participação social" e "participação cívica e emprego". Percebeu-se desta amostra que pessoas idosas com grau acadêmico mais elevado apresentam maior insatisfação frente a esta dimensão. A amostra 
justificou a necessidade de serem oferecidas oportunidades culturais que satisfaçam suas expectativas.

No Brasil a participação social foi garantida na Constituição Federal de 1988. Um dos órgãos colegiados que instituem esta participação são os Conselhos Nacionais de Direitos da Pessoa Idosa, Conselhos Estaduais de Direitos da Pessoa Idosa e Conselhos Municipais de Direitos da Pessoa Idosa.

Entretanto, estas instâncias deliberativas enfrentam muitos empecilhos para se efetivarem.

\begin{abstract}
Diante das aceleradas mudanças demográficas e da situação de vulnerabilidade da maior parte da população idosa no país, essa estratégia de governança não tem sido suficiente para assegurar a efetivação de todos os direitos previstos no marco constitucional-legal. Persistem muitos desafios para a ampliação da proteção social aos idosos no Brasil, que requerem políticas públicas orientadas para o enfrentamento das desigualdades e a expansão dos mecanismos de solidariedade entre gerações e grupos sociais (SOUZA; MACHADO, 2018, p. 3199).
\end{abstract}

Nesse viés é evidente que somente as instâncias deliberativas não são suficientes para garantir a efetivação de direitos da população idosa, ou sua participação social. É através desta participação que este segmento obtém representatividade para conquistar a garantia de direitos.

Uma das formas de garantir o que a OMS (2008) define como respeito e a inclusão social para a população idosa vulnerável é através da Política Nacional de Assistência Social.

A política de assistência social é referência no país, por "assegurar e ofertar os serviços de proteção social básica por meio dos Centro de Referência de Assistência Social - CRAS" (BRASIL, 2009b). “Os CRAS são a principal porta de entrada para os serviços do Sistema Único de Assistência Social - SUAS" (BRASIL, 2009b).

De acordo com o art. $6^{\circ} \S 1^{\circ}$, da Lei $n^{\circ} 12.435 / 2011$, que altera a Lei Orgânica de Assistência Social

[...] o CRAS é a unidade pública municipal, de base territorial, localizada em áreas com maiores índices de vulnerabilidade e risco social, destinada à articulação dos serviços socioassistenciais no seu território de abrangência e à prestação de serviços, programas e projetos socioassistenciais de proteção social básica às famílias (BRASIL, 2011a).

Para receber benefícios do governo federal, é necessário o cadastramento único CadÚnico (BRASIL, 2009b), que é realizado prioritariamente no CRAS. "O Cadúnico é um instrumento de identificação e caracterização socioeconômica das famílias brasileiras de baixa 
renda, a ser obrigatoriamente utilizado para seleção de beneficiários e integração de programas sociais do governo federal", voltados às famílias com renda de até três salários mínimos (BRASIL, 2018a).

Em 2016, o Decreto $n^{\circ}$ 8805/2016 instituiu que todos os usuários do Benefício de Prestação Continuada - BPC fossem incluídos no Cadúnico, pois até então essa inclusão não era obrigatória. Além do BPC, o referido decreto garante as famílias inseridas no Cadúnico, acesso a outros benefícios, de acordo com a renda de cada uma, como o Programa Bolsa Família; Programa Minha Casa, Minha Vida; Carteira do Idoso; Tarifa Social de Energia Elétrica; Passe Livre para Pessoas com Deficiência, Isenção de Taxas em Concursos Públicos. Para caracterizar família de baixa renda, é necessário ter uma renda familiar mensal per capita de até meio salário mínimo; ou a renda familiar mensal de até três salários mínimos (BRASIL, 2016).

Entre as pessoas idosas entrevistada nessa pesquisa, 10\% recebem BPC, 10\% Bolsa Família, 50\% estão inseridos no Cadúnico para ter acesso a outro benefício governamental, $12,5 \%$ declarou não receber benefício do governo federal, mas podem possuir outras fontes de renda, como: auxílio de familiares, recurso proveniente de alugueis de imóveis, etc. O restante $(17,5 \%)$ recebe mais de três salários mínimos, conforme demonstrado na Tabela 4. Destes dados infere-se que a maioria da amostra pesquisada em BC é público alvo da Política de Assistência Social, ou seja, 82,5\%.

Os que recebem até um salário mínimo relatam não ser o suficiente para sua subsistência, conforme a fala de Azaleia no grupo focal: "Não. Claro que não! O salário da aposentadoria é um absurdo". Orquídia completa: "[...] não tenho salário. Acredito que está para vir, como teve a greve do Instituto Nacional do Seguro Social (INSS) os idosos estão levando mais de seis meses para terem respostas de benefícios de aposentadoria". Rosa responde: "O meu filho é que paga aluguel". Lírio complementa: "[...] meu salário não é suficiente". O entrevistado Cravo relata que: "Pago luz, gás, compras, remédios e quando eu recebo já estou devendo. Só dependo desse salário, não tenho outro rendimento".

Para Ferreira e Teixeira (2014, p. 161), o processo de "[...] envelhecimento necessita de maior atenção do poder público para que a velhice possa ser vivenciada de forma digna, saudável e com pleno gozo de direitos e garantias civis, políticas e sociais", pois as pessoas idosas com renda de até um salário mínimo não conseguem prover todas as suas necessidades básicas com este recurso, como verificado entre os participantes do grupo focal. 
Tabela 4 - Perfil de renda dos entrevistados $(n=200)$. Balneário Camboriú, 2018.

\begin{tabular}{c|c|c}
\hline Respostas & Frequência & Porcentagem (\%) \\
\hline BPC & 20 & 10,0 \\
\hline Cadastro único & 114 & 57,0 \\
\hline Bolsa família & 6 & 3,0 \\
\hline $\begin{array}{c}\text { Não recebe benefício } \\
\text { governamental }\end{array}$ & 25 & 12,5 \\
\hline Mais de 3 salários & 35 & 17,5 \\
\hline Total & 200 & 100,0 \\
\hline
\end{tabular}

Fonte: Dados obtidos pelos(as) pesquisadores(as) por meio do questionário.

“O BPC é a garantia de um salário-mínimo mensal à pessoa com deficiência e ao idoso com 65 (sessenta e cinco) anos ou mais que comprovem não possuir meios de prover a própria manutenção nem de tê-la provida por sua família", art. 20 da Lei $n^{\circ} 12435$ de 6 de julho de 2011 (BRASIL, 2011a).

Ressalta-se que este benefício é custeado pela Assistência Social e administrado pelo Instituto Nacional de Seguro Social (INSS), "não pode ser acumulado pelo usuário com outro da seguridade social, exceto assistência médica ou pensão de natureza indenizatória" (BRASIL, 2011a).

Nota-se que as pessoas idosas em vulnerabilidade socioeconômica possuem apenas esta garantia legal como fonte de acesso a renda, porém somente após os 65 anos. Aqueles que tem entre 60 (sessenta) e 65 (sessenta e cinco) anos tem acesso apenas ao Programa Bolsa Família.

O Programa Bolsa Família é uma transferência de renda do governo federal e deve atender às famílias em situação de pobreza e de extrema pobreza, caracterizadas "pela renda familiar mensal per capita de até $\mathrm{R} \$ 178,00$ (cento e setenta e oito reais) e $\mathrm{R} \$ \mathbf{8 9 , 0 0}$ (oitenta e nove reais), respectivamente, de acordo com o art. $18^{\circ}$ do Decreto $\mathrm{n}$ 9 9.396, de 30 de maio de 2018" (BRASIL, 2018a).

Os participantes desta pesquisa foram questionados se ainda exercem alguma atividade remunerada. Segundo Guimarães (2012), a longevidade e a atividade produtiva são realidades no universo das pessoas com mais de sessenta anos, seja para contribuir com a renda familiar ou para garantir a autonomia. Ressalta-se que o trabalho após os sessenta anos pressupõe para a sociedade que o indivíduo continua ativo e independente. 
Em BC, 85\% dos entrevistados declararam não trabalhar no momento da pesquisa e 15\% estão inseridos no mercado de trabalho. É importante salientar que muitos envelhecentes trabalham na informalidade. Os dados nacionais apontam que "em 2006, 40\% trabalhavam por conta própria; dos idosos aposentados, $19 \%$ estavam trabalhando e $5 \%$ do mercado de trabalho era ocupado por idosos" (WALTER, 2010, p. 201). Desta forma compreende-se que tanto a nível nacional, como municipal existem idosos exercendo atividade laborativa para complementar a renda familiar.

Guimarães (2012), afirma que o trabalho informal ou autônomo, é uma alternativa para complementar a renda familiar e manter a independência, pois muitas vezes o valor da aposentadoria é inferior ao recebido durante a vida laboral anterior. Porém, esse tipo de atividade está relacionado a baixos salários e condições precárias. Infere-se a necessidade de ampliar as oportunidades de acesso ao mercado de trabalho para pessoas com mais de sessenta anos através de incentivo do Estado, não somente em BC, mas no país inteiro. Esta é uma forma de garantir o trabalho formal, que configura uma relação empregatícia com garantias legais para o trabalhador com mais de sessenta anos.

Nesse viés de garantia de emprego e renda, é fundamental retomar a discussão acerca da a importância dos CRAS no atendimento à população idosa usuária da política de assistência social, pois através deste equipamento pode-se oferecer cursos profissionalizantes e de requalificação para o trabalho, bem como estabelecer parcerias com empresas para contratar estes trabalhadores.

O art. $6^{\circ}$ da Lei Orgânica de Assistência Social, Lei $n^{\circ}$ 12.435/2011 define a proteção social básica que é ofertada no CRAS

[...] como o conjunto de serviços, programas, projetos e benefícios da assistência social que visa a prevenir situações de vulnerabilidade e risco social por meio do desenvolvimento de potencialidades e aquisições e do fortalecimento de vínculos familiares e comunitários (BRASIL, 2011a, p. 4).

A presente pesquisa demonstra que $62,5 \%$ dos entrevistados em $B C$ não conhecem e/ou nunca receberam atendimento no CRAS. Dentre os participantes do grupo focal e que frequentam o CRAS, apresenta-se no relato de Antúrio a seguinte afirmação: "Participo na quarta-feira no CRAS. Tem uma roda comunitária, eu participo e ajudo. Conversamos sobre tudo. Vai o pessoal do posto mede a pressão. Na última quarta do mês vem a médica, faz as perguntas para saber se precisamos de alguma coisa". Portanto, identifica-se na tabela 4 a 
heterogeneidade do perfil de renda dos pesquisados, que de acordo com os dados apresentados, caracterizam-se em sua maioria como usuários da política de assistência social e desconhecem os serviços disponíveis e o equipamento que deveria ser a porta de entrada para acessarem seus direitos.

O relato de Antúrio demonstra que existe uma articulação intersetorial entre a política de saúde e assistência social, conforme preconizado nas legislações que embasam as referidas políticas (SUS e SUAS). As rodas de conversa com a comunidade são apreciadas e demonstram que os participantes percebem estes espaços como uma oportunidade de contribuição com o grupo em que se encontram. Portanto, esses encontros podem ser considerados uma forma de resistência a vulnerabilidade que vivenciam.

A vulnerabilidade social está relacionada à forma como indivíduos, famílias ou grupos sociais controlam as forças que afetam seu bem-estar e ativos que constituem os recursos requeridos para o aproveitamento das oportunidades que Ihes são propiciadas. Esses ativos podem ser divididos em: físicos, humanos e sociais (MAIA, 2011 apud RINCO; LOPES; DOMINGUES, 2012, p. 85).

Para reverter essa situação entende-se que é preciso empoderar os indivíduos para que se organizem em suas comunidades, desenvolvam sua autonomia e criem redes de apoio mútuo para conquistarem seus direitos.

Nesse sentido é saliente a importância dos serviços, benefícios, programas e projetos de proteção as famílias em vulnerabilidade social. A obrigatoriedade dessas ações é exclusiva do Estado que, através da criação das políticas sociais, cria serviços, programas, projetos e ofertas de benefícios (LIMA; FORTUNA; MIGUITA, 2016, p. 44).

Os participantes da pesquisa foram questionados se já haviam sido atendidos nos Centros de Referência Especializado de Assistência Social - CREAS (BRASIL, 2011b). Diferente do CRAS que faz a prevenção de situações de risco, realiza ações de prevenção e fortalecimento de vínculos familiares e comunitários, o CREAS atende famílias em que algum de seus membros são vítima de violência.

Dentre as pessoas idosas entrevistadas, $79,0 \%$ responderam que nunca foram atendidos, $12,5 \%$ já receberam atendimento e 8,5\% não respondeu ou relatou não saber.

O CREAS é a unidade pública de abrangência e gestão municipal, estadual ou regional, destinada à prestação de serviços a indivíduos e famílias que se encontram em situação de risco pessoal ou social, por violação de direitos ou contingência, que demandam intervenções especializadas da proteção social especial (BRASIL, 2011b, p. 23). 
De acordo com a Resolução no 109, de 11 de dezembro de 2009, que define a Tipificação Nacional dos Serviços Socioassistenciais, o CREAS pode ofertar os seguintes serviços:

\begin{abstract}
Serviço de Proteção e Atendimento Especializado a Famílias e Indivíduos - PAEFI; Serviço de Proteção Social a Adolescentes em Cumprimento de Medida Socioeducativa de Liberdade Assistida e de Prestação de Serviços à Comunidade; Serviço Especializado em Abordagem Social e Serviço de Proteção Social Especial para Pessoas com Deficiência, Idosas e suas Famílias, sendo este o que atende pessoas idosas que enfrentam violação de direitos (BRASIL, 2009a).
\end{abstract}

Como é possível observar, quase $80 \%$ das pessoas idosas desta amostra desconhecem esse serviço. Este dado traz um questionamento peculiar, pois, ou a população idosa deste município não sofre nenhuma violação de direitos, o que provavelmente é inverídico devido ao estigma da sociedade em relação a velhice; ou ignora situações que lhe trazem sofrimento; ou a divulgação e encaminhamentos para este equipamento era ineficaz quando esta pesquisa foi realizada.

Salienta-se que a violência contra a pessoa idosa tem por fundo a representação social negativa sobre a velhice.

\begin{abstract}
A violência que as pessoas idosas sofrem em todo o mundo se caracteriza por ser generalizada, habitualmente não se denuncia, e tem custos econômicos e humanos muito difíceis de serem pagos pelos governos. Existem muitas razões para que as pessoas sofram violência, entre as mais frequentes estão a deteriorização e a fragilização das relações familiares. Outras causas estão associadas ao estresse do cuidador, ao isolamento social e, também, ao desequilíbrio de poder entre a vítima e o agressor. A atenção a uma pessoa enferma e dependente é um peso para qualquer pessoa. Quando os cuidadores têm um escasso apoio da comunidade, podem sofrer estresse e apresentar comportamentos que levem ao abuso e a violência (MOREIRA et al., 2016, p. 1327).
\end{abstract}

Nesse sentido é fundamental compreender que a violência contra a pessoa idosa existe, e é necessário que toda a população conheça serviços, programas e projetos que trabalhem com o enfrentamento desta questão.

O Programa Abraço ao Idoso assegura orientação e acolhimento a quem possui 60 anos ou mais e reside no município de BC. Foi instituído através da lei municipal n 4309/2019 (BALNEÁRIO CAMBORIÚ, 2019). Diferentemente do CREAS, este programa atende em regime de plantão 24 horas, situações de urgência e emergência, relacionadas à violência contra à pessoa idosa, por meio de atendimento presencial na sede do programa em horário comercial e por sobreaviso, com chamadas por telefone. Ademais, oferece abrigamento temporário em situações de violência extrema e acompanhamento integral de casos específicos. Não se 
caracteriza como um serviço de segurança pública, não realiza investigação sobre as circunstâncias em que ocorreram a violência. $O$ trabalho consiste em atendimento, orientação e apoio. Entre as pessoas idosas entrevistadas, 64\% referiram conhecer o Programa Abraço ao Idoso, $31,5 \%$ desconhecem e 4,5\% não responderam à pergunta. Dos participantes que conhecem o programa, 25,5\% responderam já terem sido atendidos. No ano de 2018 o programa Abraço foi premiado pelo Ministério da Saúde (MS) e Fiocruz como uma das quatorze melhores experiências no campo da saúde da pessoa idosa do Brasil (FIOCRUZ, 2018).

Observa-se que BC é um dos poucos municípios que oferta abrigo temporário para pessoas idosas que sofrem violência, e não podem permanecer na residência, pois correm algum risco. Nesse contexto observa-se como positivo existir um programa municipal de proteção aos direitos da pessoa idosa, mas que deve se articular com os serviços existentes.

\section{Considerações Finais}

A presente análise demonstrou que apesar de BC ser considerado nacionalmente como pioneiro em políticas públicas para a população idosa, assim como outros entes que compõem o Estado brasileiro, precisa ampliar a oferta de benefícios, serviços, programas e projetos em prol da garantia dos direitos da população idosa. Considerando a história de políticas destinadas ao envelhecimento, esse é um processo em permanente construção, e iniciativas de apoio de organismos governamentais e não governamentais são fundamentais.

A OMS (2008) define 8 (oito) dimensões para promover o envelhecimento ativo e saudável da população idosa: ambiente físico; moradia; transporte; participação; oportunidade de aprendizagem; comunicação e informação; apoio, cuidado e saúde; turismo e lazer; e; respeito e inclusão social. Considerando que a sociedade tem como modo de produção o sistema capitalista, atualmente na fase do capitalismo financeiro (LIMA; FORTUNA; MIGUITA, 2016) pode-se entender como contraditório garantir esta gama de direitos a população idosa. Entretanto, deve-se sempre dialogar, analisar e discorrer sobre o assunto no intuito de criar meios para a inversão deste modo de produção.

Referente a dimensão, respeito e inclusão social, que é o foco desta análise, percebeuse que em BC $35 \%$ da amostra não participa de nenhuma atividade de convivência e/ou fortalecimento de vínculos, justificando desinteresse, ou que as atividades oferecidas não são 
as que eles desejam em frequentar. Dados semelhantes foram encontrados em outros estudos, como os realizados em Belo Horizonte, Minas Gerais e Coimbra, Portugal.

Nesse sentido é evidente a necessidade de ouvir a população idosa ao planejar serviços, programas e projetos, bem como expandir essas ações para outros territórios do município promovendo o acesso daqueles que residem em áreas distantes do Centro.

Quanto aos espaços de discussão coletiva de direitos, como por exemplo conselhos de direitos e associação de moradores, 98\% relataram não participar destes espaços em BC. Ressalta-se que a participação social nestas instâncias é fundamental para a fruição de direitos. Apesar do Brasil possuir legislações contundentes, como a Constituição Federal, o Estatuto do Idoso e a Lei Orgânica de Assistência Social, sem a participação social é impossível efetivá-las.

Este estudo apresenta como um dos instrumentos fundamentais para a garantia de direitos da população idosa, os benefícios, serviços, programas e projetos do governo federal, como o CadÚnico, o CRAS e o CREAS que estão previstos na Lei Orgânica de Assistência Social.

Entretanto, entende-se que existem outros serviços, de outras políticas públicas extremamente relevantes, mas optou-se por estes por estarem previstos numa legislação federal e terem como um de seus objetivos fomentar a participação social.

Nesse viés em BC, 57\% dos entrevistados estão incluídos no Cadúnico, em paradoxo, $62,5 \%$ desconhece os outros serviços oferecidos nos CRAS, demonstrando que muitos podem estar fazendo o cadastramento sem compreender seus direitos; $12,5 \%$ já foram atendidos no CREAS. Nesse sentido, mais um dado evidencia a necessidade de ampliar e qualificar a divulgação e informação sobre os serviços socioassistenciais oferecidos numa linguagem acessível à população idosa. Esta dificuldade de acesso à informação é evidenciada nos documentos similares supracitados, demonstrando que é generalizado o pouco investimento em informação em linguagem acessível para pessoas acima de 60 (sessenta) anos, o que dificulta a efetivação das garantias legais.

Referente ao acesso ao mercado de trabalho, $85 \%$ dos entrevistados não trabalham e 15\% exercem atividade laborativa em BC. Uma das maneiras de garantir a participação para aqueles envelhecentes que desejam trabalhar é através do acesso ao mercado de trabalho. Nesse sentido, é imprescindível o incentivo fiscal as empresas para a contratação de pessoas idosas. 
É importante ressaltar que o estudo realizado em BC, referente a percepção das pessoas idosas frente ao respeito e inclusão social foi realizado em meados de 2018, portanto, os dados acima descritos se referem a percepção dos participantes no momento da pesquisa. Após este estudo o município desenvolveu novas políticas em prol da população idosa, como - Programa Viver, a Casa da Mulher, Programa Bem Estar da Família, Projetos Intergeracionais, reforma e entrega a comunidade de centros comunitários articulando e desenvolvendo serviços nos bairros..., o que pode ter influído na opinião delas sobre os benefícios, serviços, projetos e programas ofertados.

Frente ao apoio dos técnicos da OMS para a Rede de Cidades e Comunidades Amigáveis a população idosa, bem como do governo federal na Estratégia Brasil Amigo da Pessoa Idosa, entendeu-se ser uma iniciativa proveitosa, pelas equipes técnicas destes organismos trocarem conhecimento com as equipes municipais. Outro fator preponderante das duas iniciativas é priorizarem a escuta e participação da população idosa na elaboração do Diagnóstico Municipal da Pessoa Idosa e na elaboração do Plano Municipal da Pessoa Idosa, garantindo o protagonismo deste segmento nesta garantia de direitos.

Ressalta-se que por elaborar o Diagnóstico e Plano de Ação, BC foi a 5ạ cidade do Brasil a fazer parte da Rede de Cidades e Comunidades Amigáveis a população idosa pela OMS em 2019. Referente à Estratégia Brasil Amigo da Pessoa Idosa a gestão municipal está elaborando os próximos passos para receber a certificação de Selo Bronze, com intuito de promover políticas públicas com foco no envelhecimento ativo e saudável da população idosa, demonstrando comprometimento com a transformação dos indicadores supracitados.

\section{Referências}

BALNEÁRIO CAMBORIÚ. Decreto $\mathbf{n}^{\circ}$ 8847, de 14 de fevereiro de 2018. Regulamenta o Fundo Municipal do Idoso de Balneário Camboriú - FMIBC, criado através da Lei Municipal no 3.888/2015 e da outras providências. Balneário Camboriú: Prefeitura Municipal, 2018. Disponível em: https://leismunicipais.com.br/a1/sc/b/balneariocamboriu/decreto/2018/884/8847/decreto-n-8847-2018-regulamenta-o-fundo-municipaldo-idoso-de-balneario-camboriu-fmibc-criado-atraves-da-lei-municipal-n-3888-2015-e-daoutras-providencias. Acesso em: 17 jul. 2019.

BALNEÁRIO CAMBORIÚ. Lei $\mathbf{n}^{\circ}$ 3461, de 15 de junho de 2012. Cria a Secretaria da Pessoa Idosa - SPI, bem como dispõe sobre seu quadro de cargos de provimento em comissão e dá outras providências. Balneário Camboriú: Prefeitura Municipal, 2012. Disponível em: https://leismunicipais.com.br/a/sc/b/balneario-camboriu/lei-ordinaria/2012/346/3461/leiordinaria-n-3461-2012-cria-a-secretaria-da-pessoa-idosa-spi-bem-como-dispoe-sobre-seu- 
quadro-de-cargos-de-provimento-em-comissao-e-da-outras-providencias. Acesso em: 18 jul. 2019.

BALNEÁRIO CAMBORIÚ. Lei $\mathbf{n}^{\circ} \mathbf{3 8 8 8}$, de 28 de dezembro de 2015. Dispõe sobre as novas regras que disciplinam a política municipal da pessoa idosa e dá outras providências. Balneário Camboriú: Prefeitura Municipal, 2015. Disponível em: https://leismunicipais.com.br/a/sc/b/balneario-camboriu/lei-ordinaria/2015/389/3888/leiordinaria-n-3888-2015-dispoe-sobre-as-novas-regras-que-disciplinam-a-politica-municipalda-pessoa-idosa-e-da-outras-providencias. Acesso em: 09 mai. 2019.

BALNEÁRIO CAMBORIÚ. Lei $\mathbf{n}^{\circ}$ 4309, de 09 de setembro de 2019. Dispõe sobre a criação do "Programa Abraço ao Idoso", institui sua Equipe Técnica, e dá outras providencias. Balneário Camboriú: Prefeitura Municipal, 2019. Disponível em:

https://leismunicipais.com.br/a/sc/b/balneario-camboriu/lei-ordinaria/2019/431/4309/leiordinaria-n-4309-2019-dispoe-sobre-a-criacao-do-programa-abraco-ao-idoso-institui-suaequipe-tecnica-e-da-outras-providencias. Acesso em: 20 out. 2019.

BALNEÁRIO CAMBORIÚ. Lei $\mathbf{n}^{\circ}$ 4019, de 04 de janeiro de 2017. Autoriza o Poder Executivo a instituir a Fundação Municipal do Idoso, e dá outras providências. Balneário Camboriú: Prefeitura Municipal, 2017. Disponível em: https://leismunicipais.com.br/a/sc/b/balneariocamboriu/lei-ordinaria/2017/402/4019/lei-organica-balneario-camboriu-sc. Acesso em: 17 jul. 2019.

BOGDAN, Robert. Investigação qualitativa em educação: uma introdução à teoria e aos métodos. 12. ed. Porto: Editora Porto, 2013.

BRASIL. Câmara dos Deputados. Decreto no 9.396, de 30 de maio de 2018. Altera o Decreto no 5.209, de 17 de setembro de 2004, e o Decreto no 7.492, de 2 de junho de 2011, para reajustar valores referenciais de caracterização das situações de pobreza e de extrema pobreza e os de benefícios do Programa Bolsa Família. Brasília: Câmara dos Deputados, 2018a. Disponível em: https://www2.camara.leg.br/legin/fed/decret/2018/decreto-939630-maio-2018-786811-publicacaooriginal-155748-pe.html. Acesso em: 25 mar. 2020.

BRASIL. Ministério do Desenvolvimento Social. Estratégia Brasil Amigo da Pessoa Idosa. Brasília, DF: Ministério do Desenvolvimento Social, 2018b. Documento Técnico 1. Disponível em:

https://www.mds.gov.br/webarquivos/publicacao/Brasil_Amigo_Pesso_Idosa/Documento_ Tecnico_Brasil_Amigo_Pessoa_Idosa.pdf. Acesso em: 3 ago. 2019.

BRASIL. Lei $\mathbf{n}^{\circ} \mathbf{1 0 . 7 4 1}$, de $1^{\circ}$ de outubro de 2003. Dispõe sobre o Estatuto do Idoso e dá outras providências. Brasília: Presidência da República, 2003. Disponível em:

http://www.planalto.gov.br/ccivil_03/leis/2003/I10.741.htm\#: :text=LEI\%20No\%2010.741\% 2C\%20DE\%201\%C2\%BA\%20DE\%20OUTUBRO\%20DE\%202003.\&text=Disp\%C3\%B5e\%20sobr e\%20o\%20Estatuto\%20do\%20ldoso\%20e\%20d\%C3\%A1\%20outras\%20provid\%C3\%AAncias. \&text=Art.,a\%2060\%20(sessenta)\%20anos. Acesso em: 2 fev. 2019.

BRASIL. Lei $n^{\circ}$ 12.435, de 6 de julho de 2011. Altera a Lei $n=8.742$, de 7 de dezembro de 1993, que dispõe sobre a organização da Assistência Social. Brasília: Presidência da República, 2011a. Disponível em: http://www.planalto.gov.br/ccivil_03/_ato2011- 
2014/2011/lei/l12435.htm. Acesso em: 9 mai. 2019.

BRASIL. Ministério do Desenvolvimento Social. Estratégia Brasil Amigo da Pessoa Idosa. Brasília, DF: Ministério do Desenvolvimento Social, 2018c. Guia de Orientação 2. Disponível em:

http://www.mds.gov.br/webarquivos/publicacao/Brasil_Amigo_Pesso_Idosa/Guia_Orientac ao_Brasil_Amigo_Pessoa_Idosa.pdf. Acesso em: 3 ago. 2019.

BRASIL. Ministério de Desenvolvimento Social e Agrário. Manual Prático para Elaboração do Diagnóstico Municipal. Brasília: MDSA, 2018d.

BRASIL. Ministério do Desenvolvimento Social e Combate à Fome. Orientações técnicas: Centro de Referência de Especializado de Assistência Social - CREAS. Brasília: Editora Brasil, 2011b.

BRASIL. Ministério do Desenvolvimento Social e Combate à Fome. Resolução n. 109, de 11 de novembro de 2009. Aprova a Tipificação Nacional de Serviços Socioassistenciais. Diário Oficial da União: seção 1, Brasília, DF, n. 225, p. 82, 25 nov. 2009a. Disponível em: http://www.mds.gov.br/webarquivos/legislacao/assistencia_social/resolucoes/2009/Resolu cao\%20CNAS\%20no\%20109-\%20de\%2011\%20de\%20novembro\%20de\%202009.pdf. Acesso em: 30 out. 2019.

BRASIL. Ministério do Desenvolvimento Social e Combate à Fome. Orientações técnicas: Centro de Referência de Assistência Social - CRAS. Brasília: MDSA, 2009b.

BRASIL. Decreto $\mathbf{n}^{\circ} \mathbf{8 . 8 0 5}$, de 7 de julho de 2016. Altera o Regulamento do Benefício de Prestação Continuada, aprovado pelo Decreto no 6.214, de 26 de setembro de 2007. Brasília: Presidência da República, 2016. Disponível em:

http://www.planalto.gov.br/ccivil_03/_ato2015-2018/2016/decreto/d8805.htm. Acesso em: 25 out. 2019.

FERREIRA, A. P.; TEIXEIRA, S. M. Direitos da pessoa idosa: desafios à sua efetivação na sociedade brasileira. Argumentum, Vitória, v. 6, n. 1, p. 160-173, jan./jun. 2014.

FIOCRUZ. Saúde da pessoa idosa: boas práticas: programa abraço. Rio de Janeiro: Fiocruz, 2018. Disponível em: https://saudedapessoaidosa.fiocruz.br/programa-abra\%C3\%A7o. Acesso em: 30 out. 2019.

GATTI, B. A.. Grupo focal na pesquisa em ciências sociais e humanas. Brasília: Liber Livro Editora, 2012.

GUIMARÃES, I. B. Os idosos em um contexto de trabalho e de disposições renovadas. Mediações, Londrina, v. 17, n. 2, p 108-125, 2012.

IBGE. Censo Demográfico 2010 - famílias e domicílios: resultados da amostra. Rio de Janeiro: IBGE, 2012.

IBGE. Pesquisa Nacional por Amostra de Domicílios Contínua: características dos moradores e domicílios. Rio de Janeiro: IBGE, 2018. 
LIMA, T. A. dos S.; FORTUNA, S. L. de A.; MIGUITA, S. Algumas ponderações sobre o processo de trabalho do/da assistente social no âmbito do Sistema Único de Assistência Social - SUAS. Serviço Social \& Realidade, Franca, v. 25, n. 1, p. 31-49, 2016. Disponível em:

https://ojs.franca.unesp.br/index.php/SSR/article/view/2505/2211 Acesso em: 26 jun. 2020.

MOREIRA, W. C. et al. Análise sobre as políticas públicas de enfrentamento a violência contra o idoso. Revista de Enfermagem UFPE, Recife, v. 10, n. 4, p. 1324-1331, abr. 2016.

OMS - ORGANIZAÇÃO MUNDIAL DE SAÚDE. Guia global: cidade amiga do idoso. Genebra: OMS, 2008. Disponível em: https://www.who.int/ageing/GuiaAFCPortuguese.pdf. Acesso em: 2 out. 2019.

PAIVA, N. M.; DANIEL, F.; SILVA, A. G.; VICENTE, H. T. Coimbra, cidade amiga da(s) idade(s): percepção da cidade e qualidade de vida de uma amostra de pessoas idosas. Ciênc. saúde coletiva, Rio de Janeiro, v. 24, n. 4, p. 1423-1482, abr. 2019. Disponível

em: http://www.cienciaesaudecoletiva.com.br/artigos/coimbra-cidade-amiga-das-idadespercepcao-da-cidade-e-qualidade-de-vida-de-uma-amostra-de-pessoasidosas/16365?id=16365. Acesso em: 14 mar. 2020.

PORTO, C. F.; REZENDE, E. J. C. Experiência da aplicação do guia global da cidade amiga do idoso em uma região de Belo Horizonte-MG. Estudos Interdisciplinares sobre

Envelhecimento, Porto Alegre, v. 3, n. 3, p. 47-75, dez. 2018.

RINCO, M.; LOPES, A.; DOMINGUES, M. A. Envelhecimento e vulnerabilidade social: discussão conceitual à luz das políticas públicas e suporte social. Revista Temática Kairós Gerontologia, São Paulo, v. 15, n. 6, p. 79-95, 2012.

SEBRAE. Balneário Camboriú em números. Florianópolis: Sebrae, 2013. (Municípios Catarinenses). Disponível em:

http://www.sebrae.com.br/Sebrae/Relatório\%20Municipal\%20\%20Balneário\%20Camboriú.pdf. Acesso em: 8 out. 2019.

SOUZA, M. S.; MACHADO, Cristiani Vieira. Governança, intersetorialidade e participação social na política pública: o conselho nacional dos direitos da pessoa idosa. Ciênc. saúde coletiva, Rio de Janeiro, v. 23, n. 10, p. 3189-3200, out. 2018. Disponível em: http://www.cienciaesaudecoletiva.com.br/artigos/governanca-intersetorialidade-eparticipacao-social-na-politica-publica-o-conselho-nacional-dos-direitos-da-pessoaidosa/16821. Acesso em: 26 mar. 2020.

WALTER, M. I. M. T. A dualidade na inserção política, social e familiar do idoso: estudo comparado dos casos de Brasil, Espanha e Estados Unidos. Opinião Pública, Campinas, v. 16, n. 1, p. 186-219, jun. 2010.

Recebido em: 29.03 .2020 Aceito em: 05.06.2020 